\title{
Risk factors for complicated varicella infection in pediatric oncology patients at a tertiary health care facility in Pakistan
}

\author{
Muhammad Matloob Alam ${ }^{1}$, Farah Naz Qamar ${ }^{1}$, Zalan Wahid Khan², Vikram Kumar ${ }^{1}$, Naureen Mushtaq ${ }^{1}$, \\ Zehra Fadoo ${ }^{1}$ \\ ${ }^{1}$ Department of Pediatrics and Child Health, Aga Khan University, Karachi, Pakistan \\ ${ }^{2}$ Medical Students, Aga Khan University, Karachi, Pakistan
}

\begin{abstract}
Introduction: Varicella zoster infection(VZI) is well recognized as a potential cause of morbidity and mortality in immunocompromised pediatric oncology patients (POP). The purpose of this study was to describe the clinical profile and risk factors for complications and outcomes of VZI in POP treated with acyclovir.

Methodology: Medical records of all POP with a discharge diagnosis of VZI over a period of seven years (2005-2011) were reviewed. The demographic features, underlying malignancy, risk factors for VZI, complications, and outcomes were recorded.

Results: Thirty-six POP with VZI were identified. Leukemia was the most common underlying malignancy ( $\mathrm{n}=20,58.8 \%$ ), followed by lymphoma $(n=7,20.6 \%)$ and solid organ tumors $(n=7,20.6 \%)$. Most of the cases $(41 \%)$ were observed in children under five. All patients were treated with acyclovir. Varicella-related complications developed in $10(29 \%)$ patients. The most frequent complication was bloodstream infection $(n=3,8.8 \%)$, followed by pneumonia $(n=2,5.9 \%)$, skin infection $(n=2,5.9 \%)$, hepatitis, renal failure, and encephalitis. Independent risk factors associated with complications were age < five years, weight for age < fifth percentile, delay in seeking care ( $>$ seven days after onset of symptoms) and severe neutropenia (ANC $<500 / \mathrm{cm}$ ). One child died secondary to varicella encephalitis.

Conclusion: Our data suggests that young age, poor health-seeking behavior, severe neutropenia, and being underweight are the major risk factors for the development of varicella-related complications in POP in developing countries. These complications could be favorably modified through active immunization of immunocompetent children.
\end{abstract}

Key words: varicella; immunocompromised; oncology; acyclovir; complications

J Infect Dev Ctries 2014; 8(2):215-220. doi:10.3855/jidc.3106

(Received 30 October 2012- Accepted 03 March 2013)

Copyright (C) 2014 Alam et al. This is an open-access article distributed under the Creative Commons Attribution License, which permits unrestricted use, distribution, and reproduction in any medium, provided the original work is properly cited.

\section{Introduction}

Pediatric oncology patients are at risk of serious morbidity from varicella zoster infection (VZI) because of their primary disease as well as its treatment [1-3]. The most frequently described complications of VZI in these patients are interstitial or necrotizing pneumonia, hepatitis with acute liver failure, bacterial super infections, and post-infectious inflammatory sequelae (e.g., cerebellar ataxia, hematological abnormalities, and glomerulonephritis encephalitis) [3-8]. The varicella-related mortality in children receiving chemotherapy was around $7 \%-10 \%$ before the era of antiviral therapy, with $32 \%$ having visceral dissemination [5]. Since post-exposure prophylaxis with varicella-zoster immune globulin (VZIG) and treatment with antiviral therapy were implemented, deaths from varicella are now very rare [9]. However, despite the best preventive measures, VZI is a significant clinical problem in pediatric oncology patients, especially in developing countries where the varicella vaccine is not included in the routine immunization schedule [10]. Thus, there are large numbers of susceptible individuals, and the issue is further compounded by the unavailability of VZIG, limiting the therapeutic options in exposed immunocompromised children. There is limited data on morbidity and mortality associated with VZI in pediatric oncology patients from developing countries, especially South Asian countries. We therefore conducted this study to describe the clinical features and to identify the risk factors associated with complicated varicella and treatment outcome of VZI in pediatric oncology patients at a tertiary heath care facility in Pakistan. 


\section{Methodology}

Study design and setting

A retrospective chart review of all pediatric oncology patients admitted with a diagnosis of VZI to the pediatric oncology unit of Aga Khan University Hospital (AKUH) in Karachi, Pakistan, over a period of seven years, between 2005 and 2011, was performed. AKUH is a 600-bed tertiary health care facility and is accredited by the international arm of the Joint Commission International Accreditation Survey (JCIA). There is a 10-bed pediatric oncology ward along with a five-bed special care unit within the Pediatric Department. A total of 11,465 patients were admitted in the last seven years; the average number of admissions was 1,638 per year. There is a separate day care facility for chemotherapy administration and blood transfusions.

\section{Patient population and definition}

Patients between one month and 15 years of age who were admitted to the pediatric oncology ward between 2005 and 2011 with a diagnosis of VZI were included. For the purpose of this study, the attending physician's clinical diagnosis of varicella, based on varicella clinical case definition, set by the United States Centers for Disease Control and Prevention (CDC)/ Council of State and Territorial Epidemiologists (CSTE) Guidelines 2009 [7,11] was accepted, since no viral cultures or serologic tests were done to confirm the diagnosis. Bloodstream infection (BSI) and pneumonia in immunocompromised patients (PNEU3) was defined according to the criteria established by CDC/NHSN guidelines [12].

\section{Data collection}

Records were retrieved using a health information management system (international classification of diseases [ICD] 2008; code 0520). The data collected included demographic features, underlying malignancy, phase of chemotherapy, duration of symptoms before admission, treatment received, and length of hospital stay. Varicella-related complications were defined as a condition or event occurring within 14 days of the onset of varicella, and to which the varicella zoster virus infection may have contributed in some measure (e.g., sepsis, pneumonia, skin infection, hepatitis, encephalitis) [5]. Laboratory data such as total leukocyte counts, absolute neutrophil counts (ANC), absolute lymphocytes counts (ALC), platelet counts, and yield of blood culture (if applicable) were retrieved. The final outcome in terms of development of complications or uneventful recovery was identified.

\section{Statistical analysis}

The overall incidence of VZI in pediatric oncology patients was determined by dividing the varicellainfected cases by the total number of admissions to the pediatric oncology unit during the study period; the yearly incidence rate was calculated by dividing the varicella-infected cases by the total number of admissions in that year. For analysis, SPSS version 20.0 was used. Frequencies were computed for qualitative variables and median and interquartile range were computed for quantitative variables. The subjects were stratified according to the development of complications. Logistic regression analysis was performed to identify the independent risk factors for development of varicella-related complications. Adjusted odds ratio and confidence intervals are reported.

\section{Ethical approval}

The study was granted exemption by the Ethical Review Board (ERB) of Aga Khan University, Karachi (2250-Ped/ERC-12).

\section{Results}

A total of 11,465 pediatric patients were admitted to the oncology ward during the study period, of which 36 developed VZI. Two patients had two episodes of varicella infections, and the two secondary cases were excluded. The demographic and clinical data of 34 pediatric oncology patients with VZI were analyzed. The estimated overall incidence rate was $0.3 \%$. Yearly incidence over the seven-year study period varied from $0.17 \%$ to $0.6 \%$.

The most common underlying malignancy was acute lymphoblastic leukemia $(\mathrm{n}=18,53 \%)$, followed by lymphoma and solid organ tumors (Table 1). The median age at diagnosis of this cohort was 6.0 (interquartile range 4.7-9.3) years. The characteristics of pediatric oncology patients who developed VZI are given in Table 1. The most common presenting symptom was a rash, developed in $78.2 \%$ of the patients and frequently accompanied by fever. Other associated symptoms included anorexia, abdominal pain, body malaise, cough, vomiting, and odynophagia. All patients were hospitalized and received intravenous acyclovir for an average of 3.7 days (range 1 to 6 days) before switching to the oral form to complete between 7 and 10 days. 
Table 1. Characteristics of pediatric oncology patients who developed varicella $(n=34)$

\begin{tabular}{|c|c|c|}
\hline \multicolumn{2}{|l|}{ Characteristics } & \multirow{2}{*}{$\frac{\text { Number }(\%)}{15(44.1)}$} \\
\hline Gender & Male & \\
\hline \multirow[t]{3}{*}{ Age in years } & $0-5$ years & $14(41.2)$ \\
\hline & $6-10$ years & $13(38.2)$ \\
\hline & $11-15$ years & $7(20.6)$ \\
\hline \multicolumn{3}{|l|}{ Type of malignancy } \\
\hline \multirow[t]{2}{*}{ Acute leukemia } & Acute lymphoblastic leukemia & $18(52.9)$ \\
\hline & Acute myeloid leukemia & $2(5.9)$ \\
\hline \multirow[t]{2}{*}{ Lymphoma } & Hodgkin's lymphoma & $4(11.8)$ \\
\hline & Non-Hodgkin's lymphoma & $3(8.8)$ \\
\hline \multirow[t]{5}{*}{ Solid tumors } & Rabdomyosarcoma & $2(5.9)$ \\
\hline & Brain tumor & $2(5.9)$ \\
\hline & Osteocsarcoma & $1(2.9)$ \\
\hline & Retinoblastoma & $1(2.9)$ \\
\hline & Renal rabdoid tumor & $1(2.9)$ \\
\hline \multirow[t]{3}{*}{ Absolute neutrophil count } & $0-500 / \mathrm{cm}$ & $6(17.6)$ \\
\hline & $501-1000 / \mathrm{cm}$ & $10(29.4)$ \\
\hline & $>1000 / \mathrm{cm}$ & $16(47.0)$ \\
\hline \multirow[t]{3}{*}{ Absolute lymphocyte count } & $0-500 / \mathrm{cm}$ & $9(26.5)$ \\
\hline & $501-1000 / \mathrm{cm}$ & $12(35.3)$ \\
\hline & $>1000 / \mathrm{cm}$ & $13(38.2)$ \\
\hline \multirow{2}{*}{$\begin{array}{l}\text { Interval between last chemotherapy and development } \\
\text { of varicella }\end{array}$} & $<2$ weeks & $20(58.8)$ \\
\hline & $>2$ weeks & $14(41.2)$ \\
\hline \multirow[t]{2}{*}{ Onset of symptoms prior to admission } & $<7$ days & $27(79.4)$ \\
\hline & $>7$ days & $7(20.6)$ \\
\hline \multirow[t]{2}{*}{ Length of stay (days) } & Stay $<7$ days & $19(55.9)$ \\
\hline & Stay $>7$ days & $15(44.1)$ \\
\hline \multirow[t]{2}{*}{ Outcome } & Discharged & $33(97.1)$ \\
\hline & Expired & $1(2.9)$ \\
\hline
\end{tabular}

Table 2. Varicella-related complications $(n=10)$

\begin{tabular}{lc}
\hline Complications & Numb \\
\hline Bloodstream infection $*$ & $3(8.8)$ \\
Pneumonia** & $2(5.9)$ \\
Skin infection & $2(5.9)$ \\
Hepatitis & $1(2.9)$ \\
Encephalitis & $1(2.9)$ \\
Renal failure & $1(2.9)$
\end{tabular}

*Isolates: Streptococcus pneumoniae, Staphylococcus epidermidis, Staphylococcus species. **One patient with pneumonia also had pleural effusion 
Table 3. Risk factors of patients who developed varicella-related complications $(n=34)$

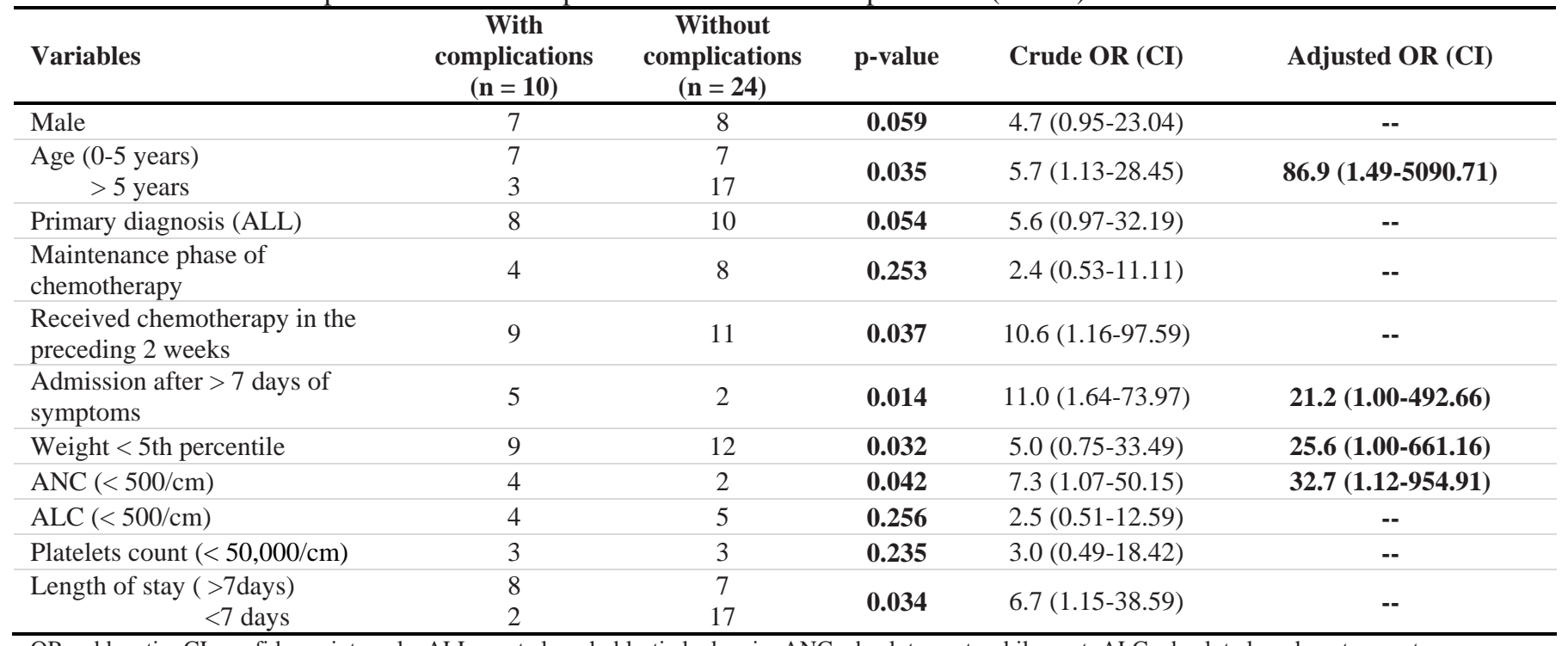

OR: odds ratio; CI: confidence intervals; ALL: acute lymphoblastic leukemia; ANC: absolute neutrophil count; ALC: absolute lymphocyte count

A total of 10 patients $(29 \%)$ developed varicellarelated complications. The most frequent complication was bloodstream infection $(\mathrm{n}=3,8.8 \%)$, followed by pneumonia $(\mathrm{n}=2,5.9 \%)$ and bacterial super infections of skin lesion ( $\mathrm{n}=2,5.9 \%)$, as shown in Table 2. On regression analysis, age under five years, delay in seeking care (> seven days after the onset of symptoms), severe neutropenia (ANC $<500 / \mathrm{cm}$ ) on admission, and being underweight ( $<$ fifth percentile) were identified as risk factors for the development of varicella-related complications among pediatric oncology patients with VZI (Table 3). The overall recovery rate was $97.1 \%$. One patient who developed varicella encephalitis expired during his stay in the intensive care unit.

\section{Discussion}

We report a high rate of varicella-related complications as compared to international data $[13,14]$. Delay in seeking care seems to be the most likely reason for this high rate. Due to multiple social, cultural, and financial constraints, care seeking is delayed as evidenced by recent data from Pakistan [15]. Lack of recommendation of the varicella vaccine in the national immunization schedule increases the risk of exposure in these high-risk children as evidenced by reports from countries where susceptible children one year of age and older in the general population are routinely vaccinated $[13,16,17]$. Hence, VZI remains a significant problem for oncology patients in developing countries where access to diagnosis and care is not readily accessible [10]. The incidence of seropositivity for varicella in the healthy population under five years of age was found to be $30 \%$, whereas up to $50 \%$ had seroconverted by adolescence in Pakistan, similar to what has been reported from other tropical countries $[18,19]$. The high percentage of seronegativity in the younger age group predisposes immunocompromised children to infection and increases their risk for exposure.

Patients with an underlying diagnosis of acute lymphoblastic leukemiaand children less than five years of age were observed to develop complications more than any other age group, which was consistent with other studies [5]. This is also explained by the high rate of seronegativity in this group.

Recently, studies have reported a varicella-related complication rate of approximately $20 \%$ in VZVinfected, immunocompromised patients treated with antiviral treatment $[3,20]$. Most subjects in these studies sought care within the first three days of the onset of symptoms. The delay in care seeking probably explains the higher complication rate seen in our study. Before the introduction of antiviral therapy, the mortality rate of VZI in children with cancer was reported to be $7 \%-10 \%$, with rates reaching up to $55 \%$ in cases with visceral involvement [5,21,22]. The majority of our patients recovered from the disease and its complications, with an overall recovery rate of $97 \%$. We report a mortality rate of $3 \%$ that is much lower than the rate reported by a previous study (13.6\%) of immunocompromised children [23].

Systemic corticosteroid therapy is said to increase morbidity, especially when administered during the 
incubation period of varicella infection [24], and is associated with fatal complications despite the administration of VZIG [25]. Children who had received immunosuppressive chemotherapy within two weeks of the development of VZI were at higher risk of complications compared to others. This implies that the more severe the immunosuppression, the greater the risk of developing varicella-related complications, as described in previous studies [9].

Post-exposure prophylaxis with VZIG has been recommended when significant exposure to varicella has occurred [26]. However, cost and unavailability limit this option [27]. All patients in our study were hospitalized for therapeutic antiviral treatment. None of our patients developed adverse effects to acyclovir as reported in other studies [20]. With the exception of one fatal case, antiviral treatment was effective in preventing mortality, though complications occurred [28]. We identified severe neutropenia as an independent risk factor for the development of varicella-related complications in our study cohort. This is in contrast to other reports in the literature, which show a higher risk of complications in lymphopenic children [5]. Varicella pneumonitis is a fatal complication, especially when ANC count is < $300 / \mathrm{cm}$, and it is associated with a $25 \%$ mortality rate [9]. However, both of our patients who had pneumonia recovered uneventfully.

Although many authors still do not recommend varicella vaccination for children receiving chemotherapy or radiotherapy because of potentially fatal complications of the vaccination, the risk associated with withholding chemotherapy and the rarity of death from VZI should be considered [4]. However, recommendation of routine varicella vaccination in the general population, especially for household contacts of immunocompromised children and caregivers who have negative history of VZI or shingles, may be the most effective practice to reduce the burden of varicella exposure, disease, and complications in these high-risk children [4,29].

Limitations of this study include its retrospective design; we were not able to assess the exposures and reasons for delay in seeking care and we may have missed patients who were not admitted and opted for outpatient or day care treatment. This was a singlecenter study; however, we assume that the results are generalizable to all developing countries where VZIG is unavailable for post-exposure prophylaxis and varicella vaccination is not part of the vaccination schedule. The small sample size explains the wide confidence intervals observed on multivariate analysis.
While the results of our study are certain, firm recommendations require additional studies.

\section{Conclusions}

Varicella-related complications develop in onethird of infected pediatric oncology patients in developing countries. Young age, poor health-seeking behavior, severe neutropenia, and being underweight are the major risk factors for the development of varicella-related complications. Treatment with antiviral therapy prevents complications and reduces mortality. However, national guidelines for varicella vaccination particularly for household contacts of this high-risk group are needed to prevent this infection from occurring.

\section{Acknowledgements}

We are thankful to Department of Pediatric and Child Health, Aga Khan University Hospital, for its support and for helping us throughout the study. No funding agency was involved for the study.

\section{References}

1. Gunawan S, Linardi P, Tawaluyan K, Mantik MF, Veerman AJ (2010) Varicella outbreak in a pediatric oncology ward: the Manado experience. Asian Pac J Cancer Prev 11: 289292.

2. Ahmed N, Heslop HE, Mackall CL (2010) T-cell-based therapies for malignancy and infection in childhood. Pediatr Clin North Am 57: 83-96.

3. Liese JG, Grote V, Rosenfeld E, Fischer R, Belohradsky BH, v Kries R, ESPED Varicella Study Group (2008) The burden of varicella complications before the introduction of routine varicella vaccination in Germany. Pediatr Infect Dis J 27: 119-124.

4. Caniza MA, Hunger SP, Schrauder A, Valsecchi MG, Pui $\mathrm{CH}$, Masera G (2012) The controversy of varicella vaccination in children with acute lymphoblastic leukemia. Pediatr Blood Cancer 58: 12-16.

5. Feldman S, Hughes WT, Daniel CB (1975) Varicella in children with cancer: Seventy-seven cases. Pediatrics 56: 388397.

6. Rack AL, Grote V, Streng A, Belohradsky BH, Heinen F, von Kries R, Liese JG (2010) Neurologic varicella complications before routine immunization in Germany. Pediatr Neurol 42: 40-48.

7. Centers for Disease Control and Prevention (2008) Epidemiology and Prevention of Vaccine-Preventable Diseases. 10th ed. Washington DC: Public Health Foundation.

8. Muller I, Aepinus C, Beck R, Bultmann B, Niethammer D, Klingebiel T (2001) Noncutaneous varicella-zoster virus (VZV) infection with fatal liver failure in a child with acute lymphoblastic leukemia (ALL). Med Pediatr Oncol 37: 145147. 
9. Feldman S, Lott L (1987) Varicella in children with cancer: impact of antiviral therapy and prophylaxis. Pediatrics 80: 465-472.

10. Roderick M, Finn A, Ramanan AV (2012) Chickenpox in the immunocompromised child. Arch Dis Child 97: 587-589.

11. Council of State and Territorial Epidemiologists (2009) Position Statement 09-ID-68. Public Health Reporting and National Notification for Varicella. CSTE. Available: http://www.cste.org/ps2009/09-ID-68.pdf Accessed on 2 October 2012

12. Horan TC, Andrus M, Dudeck MA (2008) CDC/NHSN surveillance definition of health care-associated infection and criteria for specific types of infections in the acute care setting. Am J Infect Control 36: 309-332.

13. Marin M, Meissner HC, Seward JF (2008) Varicella prevention in the United States: a review of successes and challenges. Pediatrics 122: e744-751.

14. Wootton SH, Law B, Tan B, Mozel M, Scheifele DW, Halperin S (2008) The epidemiology of children hospitalized with herpes zoster in Canada: Immunization Monitoring Program, Active (IMPACT), 1991-2005. Pediatr Infect Dis J 27: 112-118.

15. Owais A SS, Stein AD, Bashir NH, Awaldad R, Zaidi AKM (2011) Why do families of sick newborns accept hospital care quest; a community-based cohort study in Karachi, Pakistan. J Perinatol31: 586-592.

16. Asano Y, Suga S, Yoshikawa T, Kobayashi I, Yazaki T, Shibata M, Tsuzuki K, Ito S (1994) Experience and reason: twenty-year follow-up of protective immunity of the Oka strain live varicella vaccine. Pediatrics 94: 524-526.

17. Seward JF, Watson BM, Peterson CL, Mascola L, Pelosi JW, Zhang JX, Maupin TJ, Goldman GS, Tabony LJ, Brodovicz KG, Jumaan AO, Wharton M (2002) Varicella disease after introduction of varicella vaccine in the United States, 19952000. JAMA 287: 606-611.

18. Akram DS, Qureshi H, Mahmud A, Khan AA, Kundi Z, Shafi S, N-ur-Rehman, Olowokure B, Weil J, Bock H, Yazdani I (2000) Seroepidemiology of varicella-zoster in Pakistan. Southeast Asian J Trop Med Public Health 31: 646-649.

19. Wharton M (1996) The epidemiology of varicella-zoster virus infections. Infect Dis Clin North Am 10: 571-581.

20. Wiegering V, Schick J, Beer M, Weissbrich B, Gattenlohner S, Girschick HJ, Girschick HJ, Liese J, Schlegel PJ, Eyrich M(2011) Varicella-zoster virus infections in immunocompromised patients - a single centre 6-years analysis. BMC Pediatr 11: 31.
21. Matsuzaki A, Suminoe A, Koga Y, Kusuhara K, Hara T, Ogata R, Sata T, Hara T (2008) Fatal visceral varicella-zoster virus infection without skin involvement in a child with acute lymphoblastic leukemia. Pediatr Hematol Oncol 25: 237-242.

22. Katsimpardi K, Papadakis V, Pangalis A, Parcharidou A, Panagiotou JP, Soutis M, Papandreou E, Polychronopoulou S, Haidas S (2006) Infections in a pediatric patient cohort with acute lymphoblastic leukemia during the entire course of treatment. Support Care Cancer 14: 277-284.

23. Escaño-Gallardo ET, Bravo LC (2011) Varicella in immunocompromised children at Philippine general hospital: A six-year review PIDSP 12 (1).

24. Cohen JI, Brunell PA, Straus SE, Krause PR (1999) Recent advances in varicella-zoster virus infection. Ann Intern Med 130: 922-932.

25. Goldstein SL, Somers MJ, Lande MB, Brewer ED, Jabs KL (2000) Acyclovir prophylaxis of varicella in children with renal disease receiving steroids. Pediatr Nephrol 14: 305-308.

26. Salisbury D RM, Noakes K, eds (2006) Immunisation against Infectious Diseases. London: Department of Health: 421-442.

27. Gershon AA (2003) Varicella-Zoster Virus Infection. Current Treatment Options in Infectious Diseases, 5: 21-25.

28. Carcao MD, Lau RC, Gupta A, Huerter H, Koren G, King SM (1998) Sequential use of intravenous and oral acyclovir in the therapy of varicella in immunocompromised children. Pediatr Infect Dis J 17: 626-631.

29. Naqvi A, Fadoo Z, Alvi S (2010) Vaccination guidelines for children with cancer and hematopoietic stem cell transplantation living in resource-poor countries. Pediatr Blood Cancer 54: 3-7.

\section{Corresponding author}

Dr. Muhammad Matloob Alam

Fellow Pediatric Hematology \& Oncology

Department of Paediatrics \& Child Health

Aga Khan University Hospital

Stadium Road, PO Box 3500

Karachi 74800, Pakistan

Phone (+92-021) 34864795 or 092-3002802859

Fax (+9221) 34934292

Email: dr.matloobalam@hotmail.com or matloob.alam@aku.edu

Conflict of interests:No conflict of interests is declared. 